\title{
Inhalt
}

DANIEL FULDA / JÖRN STEIGERWALD

Um 1700: Die Formierung der europäischen Aufklärung. Zwischen Öffnung und neuerlicher Schließung

I. Öffnung und Schließung als Kategorien des historischen Bewusstseins und der (literatur-)historischen Forschung

DANIEL FULDA

Um 1700 begann die ,offene Zukunft'. Zum Ausgang der Aufklärung von einer allgemeinen Unsicherheitserfahrung

OLAF SIMONS

Verlagerte Problemhorizonte und produktive Problemlösungen. Alternativen zur Epochengeschichte

II. Neue Handlungsspielräume und Rollen in der Öffentlichkeit

ELENA ESPOSITO

Öffnung für das Vorläufige. Die Mode im 17. und 18. Jahrhundert..... 73

BARBARA BECKER-CANTARINO

„erlernet, dass ich meine Stimme erheben müsste“: Pietistische Ethik, Hausökonomie und Lesekultur als neue Handlungsspielräume in der Frühaufklärung

KATJA BARTHEL

Diskurse junger Männlichkeit in der Komödie um 1700 101

MARTIN MULSOW

Die Aufklärung der Dreiundzwanzigjährigen. Titelkupfer als Indikatoren für den publizistischen Hintergrund der Frühaufklärung .... 
III. Neue Methodik und Ästhetik

\section{FRANK GRUNERT}

Urteilskraft statt Gedächtnis? Von der Dequalifizierung zur erneuten

Aufwertung der Memoria in der deutschen Frühaufklärung

WOLFGANG HiRSCHMANN / BERNHARD JAHN

Oper und Öffentlichkeit. Formen impliziten Aufklärens an der Hamburger

Gänsemarktoper um 1700

IV. Übergänge

JÖRN STEIGERWALD

Roman, petit roman und nouvelle galante: Theorie und Praxis romanesken

Schreibens bei Du Plaisir

RUTH FLORACK

Transfer und Transformation: Galante Prosa zwischen Frankreich und

Deutschland

DIRK NIEFANGER

„Von dem Zustande der Poesie in Teutschland“

Die Breslauer Anleitung (1725) als erste Aufklärungspoetik

\section{Hervortreiben und Bekämpfen der Un/Ordnung}

BARRY MURNANE

„[...] kill not with Bullets, but with Pills as fatal“: das pharmazeutische

Experiment des komischen Epos um 1700.

DANIEL DUMKE

Instabile Ordnungen. ,Désordres ${ }^{6}$ als Leitmotiv in der französischen

Literatur des frühen 18 . Jahrhunderts 